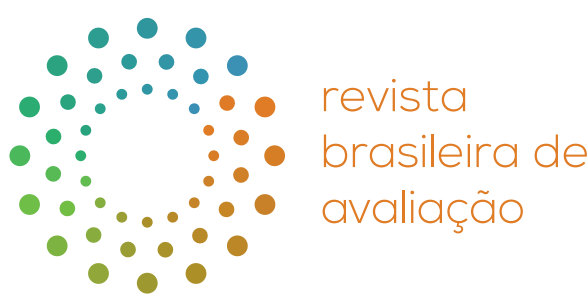

\title{
Avaliação da satisfação de usuários com os serviços da Lei Aldir Blanc: Um estudo de caso
}

\author{
Evaluation of user satisfaction with the services of the Law Aldir \\ Blanc: A case study
}

José Alberto de Siqueira Brandão ${ }^{1 *}[$ branco] (1)

${ }^{1}$ Secretaria de Planejamento e Gestão (Seplag), Recife, PE, Brasil

COMO CITAR: Brandão, José Alberto Siqueira (2022). Avaliação da satisfação de usuários com os serviços da Lei Aldir Blanc: Um estudo de caso. Revista Brasileira de Avaliação, 11(1), e110122. https://doi.org/10.4322/ rbaval202211001

\section{Resumo}

O advento da Covid-19 em todo o planeta tem provocado perdas financeiras para diversos segmentos econômicos. O segmento cultural tem sido um dos mais afetados, em face das limitações impostas pelas normas de distanciamento social. A implementação da Lei Aldir Blanc (LAB) emana como uma alternativa para mitigar os efeitos gerados para este segmento. O presente estudo objetiva avaliar a satisfação de usuários dos serviços relacionados à Lei Aldir Blanc (LAB) em Pernambuco. Para tanto, aplicou-se o modelo SERVPERF para avaliar a satisfação dos usuários dos serviços públicos prestados na gestão da referida Lei. Trata-se de um estudo de caso quantitativo, realizado mediante a aplicação de análise fatorial confirmatória do modelo proposto. Os resultados ratificam a adequação do modelo aplicado para analisar a satisfação de usuários de serviços públicos, bem como indicam uma resposta predominantemente positiva aos serviços avaliados por parte de $82 \%$ dos participantes da pesquisa.

Palavras-chave: Avaliação. Satisfação de usuários. SERVPERF. Serviços públicos. Lei Aldir Blanc.

\section{Abstract}

The advent of Covid-19 across the planet has caused financial losses for various economic segments. The cultural segment has been one of the most affected, in view of the limitations imposed by the norms of social distancing. The implementation of the Aldir Blanc Law (LAB) emanates as an alternative to mitigate the effects generated for this segment. This study aims to evaluate the satisfaction of users of services related to the Aldir Blanc Law (LAB) in Pernambuco. In this way, the SERVPERF model was applied to assess the satisfaction of users of public services provided in the management of this Law. This study is a quantitative case study, conducted through the application of confirmatory factor analysis of the proposed model. The results confirm the adequacy of the model applied to analyze the satisfaction of users of public services, as well as indicate a positive response to the services evaluated by $82 \%$ of the participants of the research.

Keywords: Evaluation. User satisfaction. SERVPERF. Public services. Aldir Blanc Law.
A RBAVAL apoia os esforços relativos à visibilidade dos autores negros na produção científica. Assim, nossas publicações solicitam a autodeclaração de cor/etnia dos autores dos textos para tornar visível tal informação nos artigos.

Recebido: Agosto 19, 2021

Aceito: Outubro 27, 2021

*Autor correspondente:

José Alberto de Siqueira Brandão E-mail: alberto.brandao@seplag. pe.gov.br

\section{(cc) BY}

Este é um artigo publicado em acesso aberto (Open Access) sob a licença Creative Commons Attribution, que permite uso, distribuição e reprodução em qualquer meio, sem restrições desde que o trabalho original seja corretamente citado. 


\section{Introdução}

Diante do contexto pandêmico que vem assolando o planeta alguns setores econômicos sofreram perdas financeiras significativas. Talvez um dos segmentos que tenha vivenciado a crise estabelecida neste contexto com mais intensidade seja o da economia criativa, em destaque especial, a cultura. Em face da necessidade de distanciamento social, as atividades da maior parcela dos agentes culturais foram suspensas ou reduziram drasticamente.

O presente artigo foi inspirado na letra que Chico Buarque ousou escrever em um tempo de dificuldades para o setor cultural, cujo título, "pra quando o carnaval chegar", retrata este cenário. Ainda que por motivos distintos, vivenciamos um estado de penúria para parte significativa dos profissionais que sobrevivem da cultura que, além de conviverem com o desprestígio caracterizado pelo fechamento do Ministério da Cultura, sofrem com a impossibilidade de apresentarem sua arte nos moldes tradicionais (Barreto, 2020). Ainda que alguns tenham se reinventado para continuar a trabalhar, a maioria não conseguiu se adaptar à nova realidade, vivendo uma crise sem precedentes na história da cultura brasileira. Parecem estar se "guardando para quando o carnaval chegar" e retornarem à ativa.

A publicação da Lei no 14.017/2020 (Brasil, 2020) soou como um salva-vidas, resgatando a esperança e a dignidade de profissionais da cultura Brasil afora. Sua denominação, Lei Aldir Blanc (doravante $L A B$ ), reverencia um grande compositor brasileiro falecido de covid-19, numa justa homenagem, ainda que póstuma. A implementação da LAB em nível nacional corresponde a uma iniciativa direcionada para ofertar ações emergenciais destinadas ao setor cultural a serem adotadas durante o estado de calamidade pública, visando amenizar os impactos da pandemia de coronavírus que assola todo o planeta e, em específico, para mitigar os efeitos observados no setor cultural do país, um dos setores mais afetados pela crise instalada a partir de tal evento.

A LAB se configura como uma conquista histórica para o setor cultural brasileiro em face de sua especificidade diante do contexto pandêmico, que praticamente inviabilizou a atuação dos profissionais do setor cultural. Coube a cada unidade da federação a incumbência de estabelecer as condições específicas para a sua implementação no âmbito de seus limites e de suas respectivas alçadas (Canedo et al., 2021).

Neste sentido foi sancionada em Pernambuco a Lei estadual n 17.057/2020 (Pernambuco, 2020b), que norteou a aplicação dos recursos emergenciais federais destinados ao segmento cultural e aos profissionais que nele atuam. A regulamentação desta Lei estadual ocorreu com a publicação do Decreto $n^{\circ}$ 49.565/2020 (Pernambuco, 2020a), que dispõe sobre a aplicação dos recursos destinados ao Estado de Pernambuco, o qual faculta a possibilidade de realização de pesquisa de satisfação com os beneficiários da política pública emergencial implementada.

Apesar de possuir amplo respaldo legal (Brasil, 2017), ainda são poucos os estudos realizados sobre avaliação de satisfação em serviços públicos, motivando a realização do presente trabalho. É importante ressaltar que sua realização contribui para que ocorram melhorias nos processos de atendimento à classe artística-cultural ainda durante o transcorrer da pandemia, haja vista a continuidade das ações da LAB.

O estudo foi desenvolvido em parceria firmada entre a Secretaria de Cultura do Estado de Pernambuco (Secult) com o Instituto de Gestão Pública de Pernambuco (IGPE), entidade componente da estrutura da Secretaria de Planejamento e Gestão (Seplag). O presente artigo tem como objetivo apresentar os resultados da avaliação de satisfação com os usuários dos serviços relacionados à política pública estabelecida na Lei Aldir Blanc (LAB) em Pernambuco, realizada entre os meses de janeiro a junho de 2021.

Ao longo do processo de desenho da avaliação de satisfação ficou definido que o estudo englobaria não apenas os beneficiários, aqui compreendidos como aqueles que obtiveram sucesso na concessão do auxílio emergencial disposto na LAB ou mediante a participação nos diferentes editais estabelecidos na legislação, mas também aqueles solicitantes e/ ou proponentes que por algum motivo não lograram êxito no processo concessivo. Desta maneira, entende-se que ocorreu uma maior abrangência do estudo, buscando obter o 
real entendimento sobre a satisfação dos usuários dos mecanismos de aplicação da LAB no contexto estadual.

\section{Procedimentos metodológicos}

Para a realização desta avaliação optou-se por desenvolver um estudo de caso mediante aplicação de pesquisa quantitativa e qualitativa. Para tanto, foi elaborado um questionário com perguntas fechadas, no formato de escala Likert de 7 pontos, considerando as escalas de concordância-discordância e satisfação-insatisfação, e perguntas abertas, ensejando a verificação de opiniões e sugestões dos participantes da pesquisa. Em todas as perguntas fechadas foram disponibilizadas alternativas adicionais para quem não soubesse responder à questão (NS), não quisesse responder à questão (NR) ou quando a questão não se aplicasse ao caso específico (NA), de modo a facultar aos participantes da pesquisa alternativas mais condizentes com sua realidade.

O questionário foi subdividido em três blocos. Para fins deste artigo, considerou-se apenas o recorte do primeiro bloco, no qual foi aplicado o modelo SERVPERF (Taylor \& Cronin, 1994), adaptado ao contexto de serviços públicos, especificamente para os serviços de administração da LAB. Composto por cinco dimensões relacionadas (confiabilidade, empatia, presteza, segurança e tangibilidade), o modelo SERVPERF procura explicar a satisfação de usuários mediante percepção do desempenho (ou da performance) dos serviços prestados que conduz à concepção de qualidade na prestação de serviços. Salomiet al. (2005, p. 282) apresentam o significado de cada dimensão da qualidade, conforme segue: “Confiabilidade: habilidade de prestar o serviço com exatidão; Presteza: disposição em ajudar os clientes e fornecer o serviço com presteza e prontidão; Garantia [segurança]: conhecimento dos funcionários e suas habilidades em demonstrar confiança; Empatia: grau de cuidado e atenção pessoal dispensado aos clientes; e Aspectos Tangíveis [tangibilidade]: aparência das instalações, equipamentos, pessoal envolvido e material de comunicação".

A escolha pelo SERVPERF se deu em função de se tratar de um modelo consolidado, confiável e válido, e que se apresenta de modo mais simples e econômico que outros modelos disponíveis, como o SERVQUAL Uain \& Gupta, 2004; Salomi et al., 2005; Carvalho, 2008; Mondo \& Fiates, 2013; Souto \& Correia-Neto, 2017).

O questionário foi encaminhado para os e-mails cadastrados pelos solicitantes e/ou proponentes na plataforma Mapa Cultural. Todo o processo de cadastramento, como o uso dos dados cadastrais respeitou as premissas estabelecidas pela Lei Geral de Proteção de Dados (Lei $n^{\circ}$ 13.709/2018), especialmente que tange à anonimização dos dados pessoais e ao respeito no trato de dados sensíveis. Foram encaminhados e-mails para 5.802 agentes culturais cadastrados, além de ter sido disponibilizado o link da pesquisa para aqueles que acessassem o Portal Cultura PE, durante um período de doze dias, tendo sido encerrado o prazo para preenchimento do questionário no dia 28/05/2021.

Alcançou-se um total de 704 respostas à pesquisa, superando a expectativa inicial de alcançar uma amostra composta por 361 participantes, com base em um grau de confiança de $95 \%$ e uma margem de erro de 5\%. Optou-se por excluir da base amostral aqueles questionários cujo nível de respostas às alternativas NS, NR ou NA fosse superior a três perguntas, o que corresponde ao terceiro quartil do total de respostas.

Desta maneira, definiu-se a amostra final com um conjunto composto por 596 participantes, cuja distribuição por tipo de acesso a LAB e por situação, pode ser observada no Quadro 1, a seguir apresentado. É possível observar a existência de interseção em virtude de ter sido facultada aos agentes culturais a possibilidade de solicitar o auxílio emergencial e propor alguma iniciativa mediante os editais dispostos na LAB. Cabe destacar ainda que não foi possível identificar informações sobre a situação de 156 participantes.

Inicialmente, procedeu-se uma análise exploratória de dados, considerando-se a distribuição de frequências e as estatísticas descritivas das variáveis. Em sequência, procedeu-se uma análise fatorial confirmatória (CFA) com as 21 variáveis observáveis componentes do 
Quadro 1. Distribuição dos usuários participantes da amostra por tipo de acesso e situação.

\begin{tabular}{|c|c|c|c|c|c|c|c|}
\hline \multicolumn{3}{|c|}{ Tipo de acesso LAB } & \multicolumn{2}{|c|}{ Incisos II e III - Editais } & \multirow{3}{*}{$\begin{array}{l}\text { Subtotal } \\
\text { Situação } \\
\text { Inciso I }\end{array}$} & \multirow[t]{3}{*}{$\begin{array}{l}\text { Subtotal Tipo } \\
\text { de Acesso LAB }\end{array}$} & \multirow[t]{3}{*}{$\begin{array}{c}\text { Sem dado/ } \\
\text { status }\end{array}$} \\
\hline \multirow{2}{*}{\multicolumn{3}{|c|}{$\begin{array}{c}\text { Situação } \\
142\end{array}$}} & Selecionado & \multirow{2}{*}{ Suplente } & & & \\
\hline & & & 102 & & & & \\
\hline \multirow{2}{*}{$\begin{array}{c}\text { Inciso } \\
\text { I - Auxílio } \\
\text { Emergencial }\end{array}$} & Deferido & 105 & 4 & 7 & 116 & \multirow{2}{*}{196} & \multirow{2}{*}{156} \\
\hline & Indeferido & 61 & 10 & 9 & 80 & & \\
\hline \multicolumn{3}{|c|}{ Subtotal Situação - Incisos II e III } & 156 & 118 & \multirow{2}{*}{\multicolumn{2}{|c|}{ Total }} & \multirow{2}{*}{596} \\
\hline \multicolumn{3}{|c|}{ Subtotal Tipo de Acesso LAB } & \multicolumn{2}{|c|}{274} & & & \\
\hline
\end{tabular}

Fonte: Mapa Cultural - Secult (2021).

modelo SERVPERF, tendo em vista a busca por entendimento de um constructo latente (não diretamente observável) que é a satisfação de usuários (Hair et al., 2009) a partir de dimensões (fatores) de um modelo anteriormente validado. Com a aplicação destes passos foi possível a elaboração da próxima seção onde são apresentados os resultados decorrentes do presente estudo.

\section{Resultados}

Para iniciar o processo de análise, procedeu-se o tratamento dos dados obtidos. Em função das características dos dados categóricos ordinais obtidos nas escalas adotadas, optou-se pela exclusão de dados ausentes por pares de variáveis (modalidade pairwise deletion), de modo a trazer um menor impacto na quantidade de observações excluídas.

Realizou-se ainda a aplicação de testes estatísticos para se verificar a confiabilidade dos dados, conforme Tabela 1. Os resultados dos testes alfa de Cronbach, Kaiser-Meyer-Olkin (KMO) e esfericidade de Bartlett, reforçaram a confiança nos dados obtidos e confirmaram a adequação para a realização da análise fatorial. Foram realizados testes de Shapiro-Wilk e Kolmogorov-Smirov para verificação de normalidade nos dados. Em ambos os testes aplicados apresentaram resultados inferiores a 0,001, indicando que os dados obtidos não se apresentam conforme uma curva normal.

Tabela 1. Testes estatísticos sobre a amostra: alfa de Cronbach, KMO e esfericidade de Bartlett.

\begin{tabular}{lcc}
\hline \multicolumn{1}{c}{ Teste Estatístico } & Resultado \\
\hline Alfa de Cronbach & & 0,992 \\
Medida Kayser-Meyer-Olkin (KMO) de adequação da amostragem & 0,983 \\
Teste de esfericidade de & Aproximação qui-quadrado & 17596,973 \\
Bartlett & Graus de liberdade (gl) & 496 \\
& Significância & 0,000 \\
\hline
\end{tabular}

Fonte: elaboração própria.

Procedeu-se a elaboração de gráfico boxplot, possibilitando uma análise visual acerca dos dados registrados para cada questão conforme a escala de 7 pontos. A Figura 1, apresentado a seguir, mostra a distribuição dos resultados para cada uma das variáveis envolvidas no estudo. Como se pode observar, ocorreu uma maior concentração das respostas em valores superiores a 4, que correspondeu ao primeiro quartil apenas em três variáveis (Q3_E, Q6_E e Q16_A). 


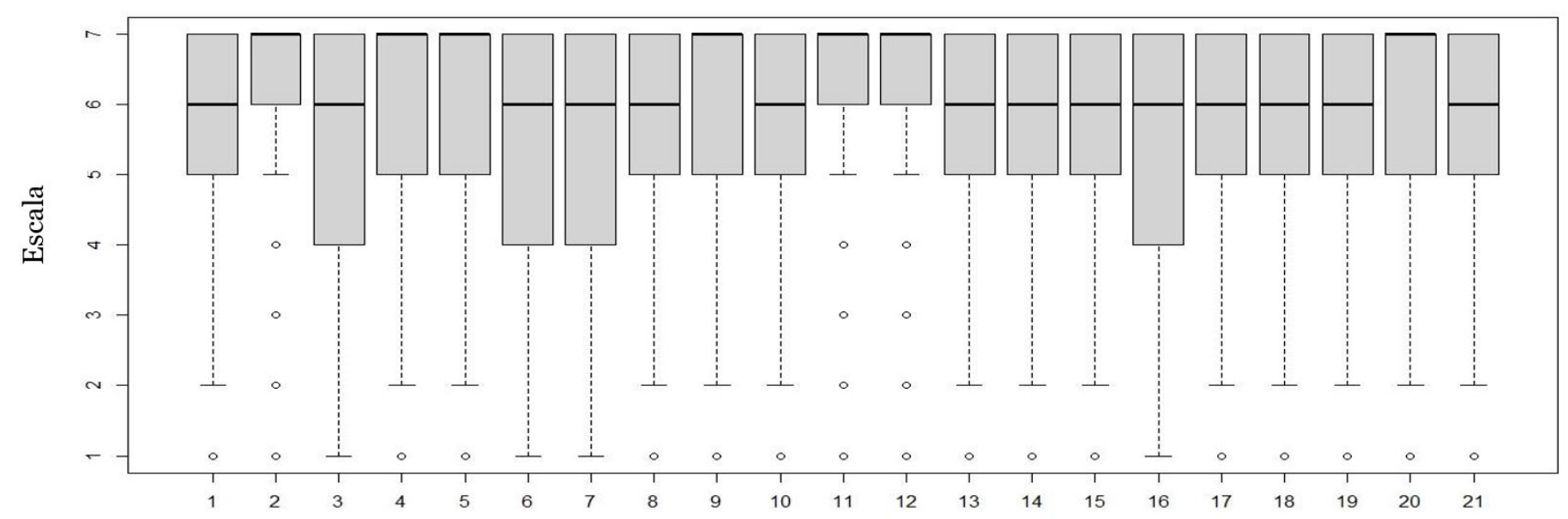

Questões

Figura 1. Distribuição dos dados das questões em formato boxplot.

Fonte: elaboração própria.

De fato, em mais de um terço das variáveis a mediana se posicionou no valor 7 , enquanto nas demais variáveis a mediana se posicionou no valor 6 , demonstrando alta concentração dos resultados em torno do valor máximo. Considerando-se que em todas as questões a amplitude calculada foi sempre igual a 6 , e que o limite superior resultou no nível 7, mas que o limite inferior na maioria dos casos ficou em 2, foi possível observar a existência de alguns outliers situados em quase todas as questões, demonstrando a presença de poucos resultados dissonantes em relação ao todo. Isto ressalta a alta concentração dos dados obtidos, ainda que presentes alguns resultados baixos apresentados como pontos fora da curva (outliers).

A partir destes dados, optou-se por desenvolver uma análise fatorial confirmatória (AFC) sobre o modelo SERVPERF, considerando a necessidade de se identificar a partir de um modelo a priori, se uma variável latente ou não observável (a satisfação de usuários) pode ser estimada mediante variáveis observáveis, a partir das respostas formuladas pelos participantes da pesquisa. Foi possível verificar a existência de correlações significativas entre as dimensões confiabilidade (C), empatia (E), presteza (A), segurança (S) e tangibilidade (T) e processo administrativo $(P)$. A Figura 2, apresentada abaixo, retrata as dimensões citadas e os fatores componentes, bem como as estimativas de pesos padronizados.

Após o resultado obtido na realização da análise fatorial confirmatória, ratificando o modelo SERVPERF, cabe discutir os resultados sob a ótica dos participantes da pesquisa com relação a cada uma das questões formuladas no questionário. Para tanto, considerando-se o uso de uma escala Likert, em que não existe necessariamente uma relação de equilíbrio na distribuição de grandeza entre os valores apresentados, optou-se por realizar a análise da mediana e das distâncias interquartílicas. A Figura 3, apresentada a seguir, demonstra o resultado geral obtido para cada uma das variáveis do modelo SERVPERF, conforme a ordem do maior resultado para o menor resultado.

É possível observar nesta Figura 3 que a variável com melhor resultado foi aquela que versa sobre adequação no atendimento com cortesia e cordialidade (Q12_E), componente da dimensão empatia, com $88 \%$ dos respondentes se posicionando de modo favorável, $4 \%$ de forma neutra e $8 \%$ de modo desfavorável. Também mereceram destaque as variáveis que versam sobre respeito à privacidade dos dados (Q11_S) e quanto ao atendimento aos compromissos assumidos (Q2_C).

Em posição antagônica, a variável que versa sobre o uso das reclamações e sugestões para melhoria do serviço (Q3_E), também componente da dimensão empatia, foi a que obteve a 


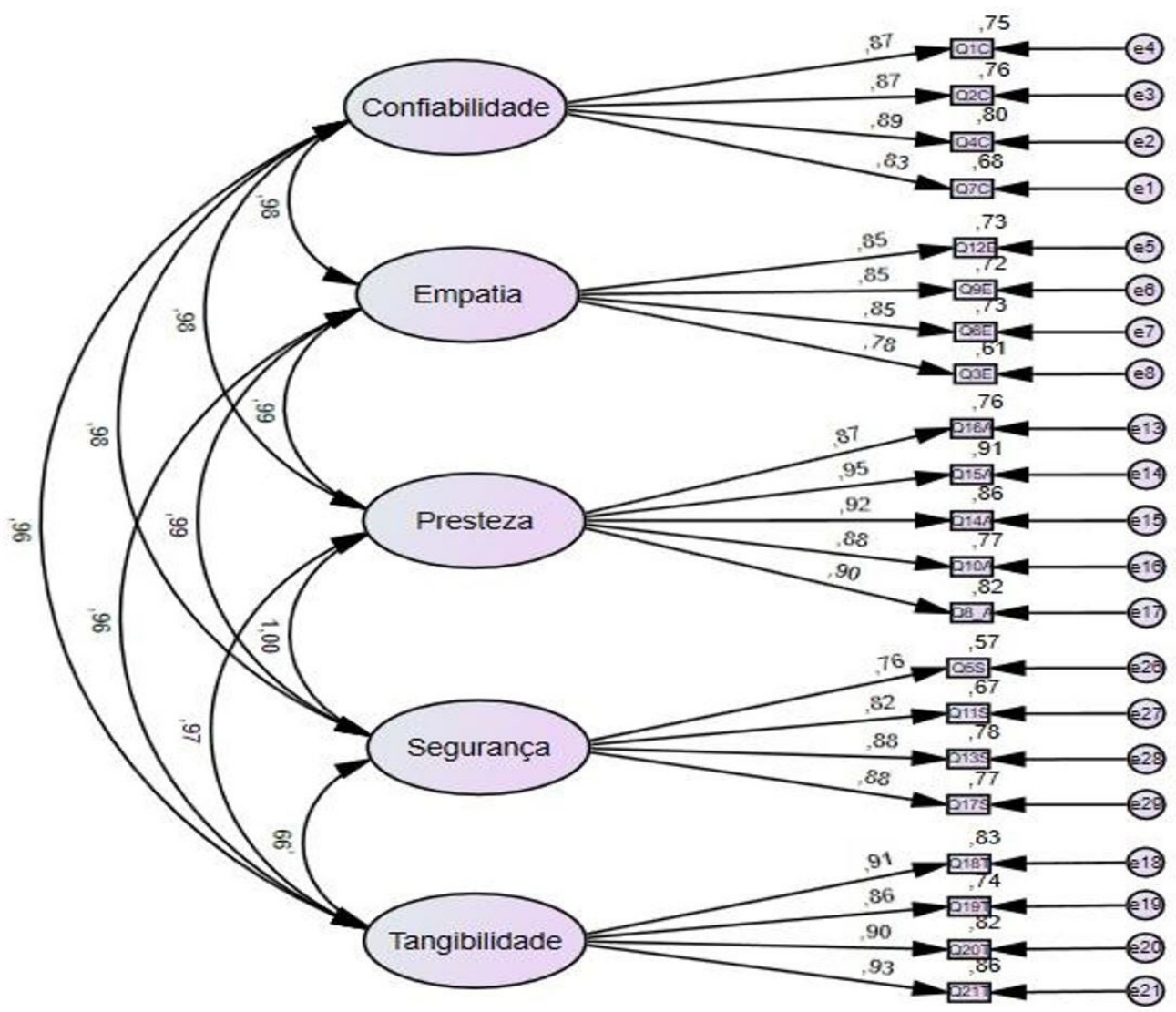

Figura 2. Modelo fatorial confirmatório com 5 dimensões e 21 fatores (SERVPERF).

Fonte: elaboração própria.

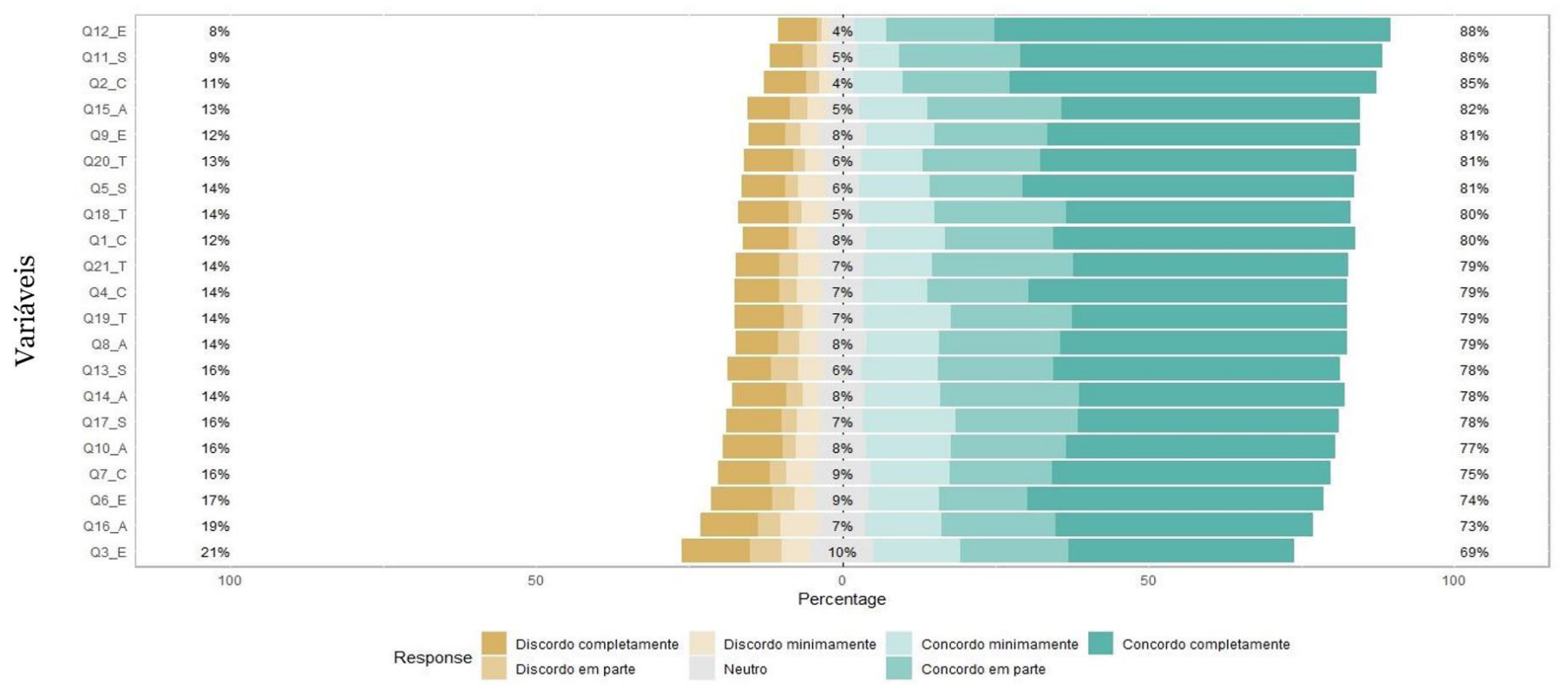

Figura 3. SERVPERF - Distribuição percentual geral dos resultados agrupados (positivo, neutro, negativo). Fonte: elaboração própria.

menor avaliação, com $69 \%$ dos respondentes se posicionando de modo favorável, $10 \%$ de forma neutra e $21 \%$ de modo desfavorável, sendo interessante iniciar um processo de melhoria do serviço mediante a implementação de ações voltadas para a melhoria deste ponto. Outras 
variáveis com desempenho menor neste estudo foram a que se referem à existência de dificuldades no processo (Q16_A) e à disponibilidade de ajuda aos usuários (Q6_E).

De modo geral, verifica-se que os resultados indicam o reconhecimento de uma qualidade de serviços superior ao desejável, representando uma resposta positiva em relação aos serviços prestados pela SECULT no âmbito da LAB. Os dados apresentados na Figura 4, ratificam esta posição, indicando maior concentração de respostas de todas as questões no nível máximo (7), mesmo na variável Q3_E, destacada como a de menor resultado.

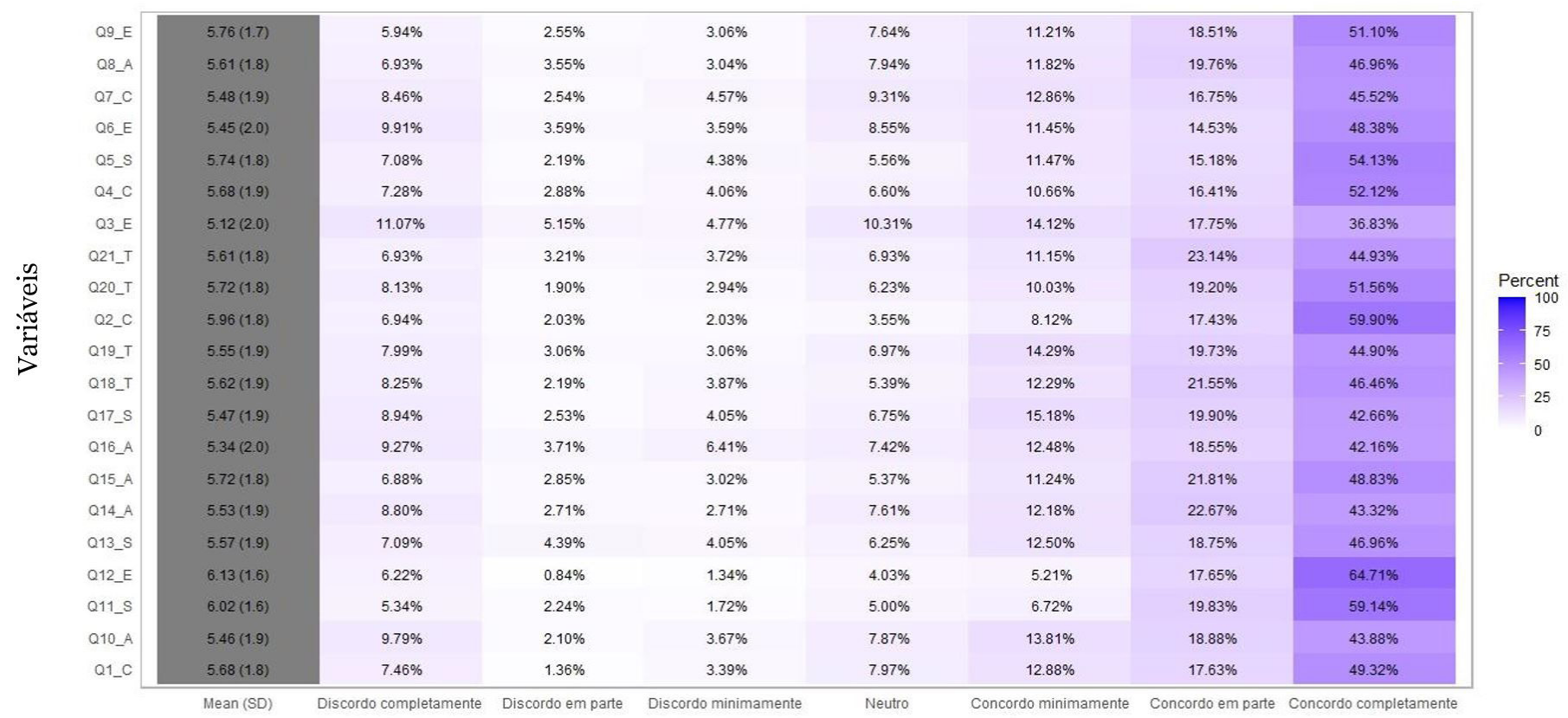

Figura 4. SERVPERF - Distribuição percentual por resposta.

Fonte: elaboração própria.

Quando solicitados a se expressarem sobre uma avaliação global da qualidade do atendimento prestado pela Secult no tocante aos serviços relativos à $L A B$, os participantes da pesquisa apresentaram posicionamento amplamente favorável, com $82 \%$ se colocando de modo positivo, enquanto $6 \%$ se posicionaram de modo neutro e $12 \%$ se posicionaram negativamente. Cabe ressaltar que 40,2\% dos entrevistados assinalaram o conceito máximo para esta pergunta. As respostas a esta questão parecem confirmar o elevado índice de satisfação dos usuários com o serviço prestado, de modo a ratificar o posicionamento ofertado nas demais questões formuladas no estudo.

\section{Considerações finais}

O presente estudo se destinou a avaliar a satisfação dos usuários dos serviços relacionados à política pública estabelecida na Lei Aldir Blanc no âmbito do Estado de Pernambuco. Para que fosse possível a identificação da variável não diretamente identificável (latente), como é o caso da satisfação dos usuários, torna-se necessária a adoção de um modelo com dimensões observáveis que venham a sinalizar a resposta desejável. Optou-se pela aplicação do modelo SERVPERF, adaptado ao contexto do serviço público específico. Aplicou-se um questionário com este modelo à uma amostra composta por um conjunto constituído por 596 usuários dos serviços relativos à $L A B$.

O modelo SERVPERF considera a satisfação dos usuários de serviços a partir do desempenho percebido, sendo constituído por 5 dimensões, sendo elas confiabilidade (C), empatia $(E)$, presteza (A), segurança (S) e tangibilidade (T). Uma das primeiras preocupações foi verificar a consistência e adequação do modelo ao caso estudado, o que foi possível mediante a 
realização de uma análise fatorial confirmatória. Após a realização dos testes requeridos pelo método adotado, os resultados alcançados ratificaram o modelo escolhido.

Considerando as características dos dados, optou-se por considerar medidas de tendência central, como mediana e distância interquartílica. Os resultados mostraram-se bastante positivos com relação ao nível de satisfação dos usuários e com relação a todas as dimensões consideradas, inclusive no tocante ao processo administrativo. Em todas as variáveis estudadas ocorreu concentração da maioria das respostas no conceito máximo (7) adotado na escala aplicada, demonstrando nitidamente a valorização proporcionada pelo usuário em relação ao serviço prestado.

A dimensão empatia foi a que demonstrou maior dispersão dos dados entre variáveis, ficando a variável sobre uso de reclamações e sugestões com a pior avaliação. Ainda assim, os resultados desta dimensão ratificaram a posição de satisfação dos usuários. De igual modo, o resultado também refletiu um nível adequado de satisfação do usuário. Tanto que na questão que sintetiza as opiniões quantitativas dos usuários, a satisfação global com o serviço prestado pela Secult alcançou um total de $82 \%$ de respostas favoráveis, $6 \%$ neutras e $12 \%$ desfavoráveis.

Podem ser identificadas como limitações do estudo o fato do cadastro na plataforma ter sido realizado pelos próprios usuários, de modo que eventuais falhas no preenchimento dos dados, especialmente relativos aos e-mails podem ter trazido prejuízos ao dificultar o contato e, por conseguinte, a participação na pesquisa. Foi identificada também a existência de repetições de e-mails nos cadastros, haja vista a faculdade dos agentes culturais poderem se cadastrar tanto para o auxílio emergencial quanto para os editais propostos pela LAB.

Como se trata de um estudo de caso realizado em nível subnacional, especificamente relacionado ao Estado de Pernambuco, o presente trabalho reflete apenas a opinião dos participantes da pesquisa, não servindo como uma generalização acerca da LAB no âmbito nacional. No entanto, funciona como estímulo para que novos estudos sejam realizados para que esta política possa ser avaliada nacionalmente, o que se configura como necessidade e como exigência legal Além do mais, como não foi possível, com base nos dados disponibilizados, realizar a distinção tempestiva entre os grupos de beneficiários do LAB com relação aos que não obtiveram êxito na concessão, fica caracterizada mais uma limitação do estudo.

É importante destacar que os resultados alcançados, apesar de alvissareiros, refletem uma realidade momentânea e precisam ser considerados como oportunidade de melhoria dos serviços prestados. Neste sentido, dentre todos os pontos apresentados pelos participantes da pesquisa, destacam-se alguns que possibilitaram a elaboração das recomendações que seguem abaixo, para que possam dar uma atenção maior na condução das próximas atividades, considerando, inclusive, que muito do que foi feito durante o processo da LAB pode ser adotado de forma permanente em outros serviços:

a) investir na qualificação de servidores e prestadores de serviços que vierem a atuar em prestação de serviços ao público do setor cultural;

b) simplificar as exigências documentais e as atividades vinculadas, de modo a tornar o processo mais simples e célere;

c) proporcionar maior qualificação dos usuários, com participação em cursos voltados para elaboração de projetos culturais, adotando os preceitos da linguagem simples, de modo a facilitar o entendimento e a participação efetiva do público-alvo;

d) aperfeiçoar a sistemática de respostas aos usuários dos serviços, de modo a prestar esclarecimentos para todos os solicitantes, especialmente para aqueles que não tenham sido contemplados, explicando os motivos para tanto; e

e) estudar estratégia de atendimento regionalizado, utilizando a estrutura física do estado já disponível em outras regiões, sobretudo naquelas em que há polos culturais robustos. 


\section{Fonte de financiamento}

Não há.

\section{Conflito de interesse}

Não há.

\section{Referências}

Barreto, Luisa Marques. (2020). Lei Aldir Blanc de emergência e o fim do Plano Nacional de Cultura (2010-2020). Boletim de Políticas Públicas/OIPP, 7(1), 29-42.

Brasil. (2017). Lei $n^{\circ} 13.460$, de 26 de junho de 2017. Dispõe sobre participação, proteção e defesa dos direitos do usuário dos serviços públicos da administração pública. Diário Oficial [da] República Federativa do Brasil, Brasília. Recuperado em 15 de agosto de 2021, de https://www.planalto.gov.br/ccivil_03/_ato20152018/2017/lei/l13460.htm

Brasil. (2020). Lei n 14.017, de 29 de junho de 2020. Dispõe sobre ações emergenciais destinadas ao setor cultural a serem adotadas durante o estado de calamidade pública reconhecido pelo Decreto Legislativo $\mathrm{n}^{\circ}$ 6, de 20 de março de 2020. Diário Oficial [da] República Federativa do Brasil, Brasília. Recuperado em 15 de agosto de 2021, de http://www.planalto.gov.br/ccivil_03/_Ato2019-2022/2020/Lei/L14017.htm.

Canedo, Daniele Pereira, Andrade, Carlos Magno Diniz Guerra, Freitas, Elizabeth Ponte, Campos, Luiz Gustavo Santana, \& Carvalho, Rosimeri. (2021). Políticas culturais emergenciais na pandemia da Covid-19: Demandas e estratégias de enfrentamento e as respostas dos poderes públicos. Política cultura revista, 14(1), 65-191.

Carvalho, Cláudia Sofia Magalhães. (2008). A qualidade do serviço público: O caso da Loja do Cidadão. (Tese de doutorado). Universidade do Porto, Porto.

Hair, Joseph. F, Black, William C., Babin, Barry J., Anderson, Rolph E., Tatham \& Ronald L. (2009). Análise multivariada de dados. Porto Alegre, RS: Bookman.

Jain, S., \& Gupta, G. (2004). Measuring service quality: Servqual vs. Servperf scales. Vikalpa, 29(2), 25-37. http://dx.doi.org/10.1177/0256090920040203

Mondo, Tiago Savi, \& Fiates, Gabriela Gonçalves Silveira. (2013). Os modelos de qualidade em serviços: Mapeamento da produção científica de alto impacto para a área de Administração no Brasil até 2012, motivo de preocupação para os pesquisadores de Marketing?. In ANPAD (Org.), XXXVII Encontro da Associação Nacional de Pós-graduação em Administração (pp. 1-16). Rio de Janeiro: ANPAD.

Pernambuco. (2020a). Decreto $n^{\circ}$ 49.565, de 15 de outubro de 2020. Regulamenta a Lei $n^{\circ} 17.057$, de 25 de setembro de 2020, que dispõe sobre a aplicação dos recursos destinados ao Estado de Pernambuco por força da Lei Federal n 14.017, de 29 de junho de 2020, para o implemento de ações emergenciais destinadas ao setor cultural, durante o estado de calamidade pública reconhecido pelo Decreto Legislativo Federal $n^{\circ}$ 6, de 20 de março de 2020. Assembleia Legislativa de Pernambuco, Recife. Recuperado em 15 de agosto de 2021, de https://legis.alepe.pe.gov.br/texto.aspx?id=52128\&tipo=.

Pernambuco. (2020b). Lei n ${ }^{\circ}$ 17.057, de 25 de setembro de 2020. Dispõe sobre a aplicação dos recursos destinados ao Estado de Pernambuco por força da Lei Federal n 14.017, de 29 de junho de 2020, para o implemento de ações emergenciais destinadas ao setor cultural, durante o estado de calamidade pública reconhecido pelo Decreto Legislativo Federal $n^{\circ} 6$, de 20 de março de 2020. Assembleia Legis/ativa de Pernambuco, Recife. Recuperado em 15 de agosto de 2021, de https://legis.alepe.pe.gov.br/texto. aspx?id=51948\&tipo $=$.

Salomi, Gilberto Gabriel Eid, Miguel, Paulo Augusto Cauchick, \& Abackerli, Alvaro José. (2005). Servqual x Servperf: Comparação entre instrumentos para avaliação da qualidade de serviços internos. Gestão \& Produção, 12(2), 279-293. http://dx.doi.org/10.1590/S0104-530X2005000200011

Secretaria de Cultura do Estado de Pernambuco. (2021). Mapa Cultural [banco de dados]. Disponível em: https://www.mapacultural.pe.gov.br/

Souto, Christiane de Melo Rêgo, \& Correia-Neto, Jorge Silva (2017). Qualidade de serviços: Uma análise comparativa entre SERVQUAL e SERVPERF. Journal of Perspectives in Management, 1(1), 63-73. http://dx.doi. org/10.51359/2594-8040.2017.231693

Taylor, Steven A., \& Cronin Junior, J. Joseph. (1994). An empirical assessment of the Servperf scale. Journal of Marketing Theory and Practice, 2(4), 52-69. http://dx.doi.org/10.1080/10696679.1994.11501669 